\title{
Genomic profiling of a combined large cell neuroendocrine carcinoma of the submandibular gland
}

\author{
SIMON ANDREASEN ${ }^{1-3}$, MARTA PERSSON $^{4}$, KATALIN KISS $^{5}$, PREBEN HOM $^{2,3}$, \\ STEFFEN HEEGAARD ${ }^{5,6}$ and GÖRAN STENMAN ${ }^{4}$
}

\author{
${ }^{1}$ Department of Otorhinolaryngology Head and Neck Surgery and Audiology, Rigshospitalet, Copenhagen; \\ ${ }^{2}$ Department of Otorhinolaryngology and Maxillofacial Surgery, Køge University Hospital, Køge; \\ ${ }^{3}$ University of Copenhagen, Faculty of Health and Medical Sciences, Copenhagen, Denmark; \\ ${ }^{4}$ Sahlgrenska Cancer Center, Department of Pathology, University of Gothenburg, Gothenburg, Sweden; \\ ${ }^{5}$ Department of Pathology, Rigshospitalet; ${ }^{6}$ Department of Ophthalmology, Rigshospitalet-Glostrup, Copenhagen, Denmark
}

Received November 27, 2015; Accepted January 5, 2016

DOI: 10.3892/or.2016.4621

\begin{abstract}
A 69-year-old female with no previous medical history presented with a rapidly growing submandibular mass. Fine needle aspiration cytology suggested a small-cell carcinoma and PET-CT showed increased 18-FDG uptake in the submandibular mass as well as in a lung mass. Submandibular resection and selective neck dissection was performed and histopathologic examination revealed a combined large-cell neuroendocrine carcinoma (LCNEC) with a squamous component and without lymph node metastases. Resection of the lung tumor revealed a papillary adenocarcinoma that was morphologically distinctly different from the LCNEC. The patient died of her lung cancer after 19 months without evidence of recurrence of the LCNEC. Genomic profiling of the salivary gland LCNEC revealed a hypodiploid genome predominated by losses of whole chromosomes or chromosome arms involving chromosomes $3 \mathrm{p}, 4,7 \mathrm{q}, 10,11,13,16 \mathrm{q}$ and gains of $3 \mathrm{q}$ and $16 \mathrm{p}$. In addition, there was a segmental gain of 9p23-p22.3 including the NFIB oncogene. Continued studies of salivary gland LCNEC may provide new knowledge concerning potential diagnostic biomarkers and may ultimately also lead to the identification of new treatment targets for patients with these aggressive carcinomas.
\end{abstract}

\section{Introduction}

Large cell neuroendocrine carcinoma (LCNEC) is a rare, aggressive malignancy most commonly arising in the lung (1). In 1990, Hui et al (2) described the first case of LCNEC in the

Correspondence to: Dr Simon Andreasen, Department of Otorhinolaryngology and Maxillofacial Surgery, Køge University Hospital, Lykkebækvej 1, DK-4600 Køge, Denmark

E-mail: simon@andreasen.pm

Key words: large cell neuroendocrine carcinoma, salivary gland, submandibular gland, arrayCGH, combined parotid gland and since then five additional cases in the parotid and four in the submandibular gland have been reported (2-10). Four of these patients have died of their disease. Similar to pulmonary LCNEC, salivary gland LCNEC shows a characteristic growth pattern, high mitotic rate and evidence of neuroendocrine differentiation, including expression of synaptophysin, chromogranin A and/or CD56 (11). When showing squamous, giant-cell, spindle-cell or adenocarcinomatous features, the tumors are designated combined LCNEC. There is no classification of salivary LCNEC in the 2005 World Health Organization (WHO) classification of head and neck tumors which is why the WHO criteria for pulmonary LCNEC are applied to this type of salivary gland tumor $(1,12)$. Clinically, salivary gland LCNEC presents as a rapidly growing mass with frequent cervical nodal metastases. Due to the extreme rarity of these tumors no recommendations have been made as to its treatment.

Little is known about the molecular pathogenesis of salivary gland LCNEC and hence it is not known whether they are genetically similar or different from LCNEC in other anatomical locations, such as for example the lung where only few reports about the genomic profile are available (13-15). Studies of the genetics of salivary gland LCNEC may provide new knowledge concerning potential diagnostic biomarkers and may ultimately also lead to the identification of new treatment targets for patients with this aggressive carcinoma. In the present study, we report a case of LCNEC of the submandibular gland, the first LCNEC with squamous features of the salivary glands (also known as combined LCNEC) (1). We also present a detailed genomic profile of the tumor based on high-resolution array comparative genomic hybridization (arrayCGH).

\section{Patient and methods}

Case report. A 69-year-old female was referred to the Department of Otorhinolaryngology Head and Neck Surgery and Audiology at Rigshospitalet (Copenhagen, Denmark) with a 3-week history of a rapidly growing mass in the right submandibular region. Clinical examination revealed a mobile, firm $3 \times 7 \mathrm{~cm}$ mass in the submandibular area. No palpable 
lymph nodes on the neck were found. Ultrasound confirmed the submandibular origin and an inhomogeneous echo pattern of the tumor. Fine needle aspiration cytology (FNAC) showed carcinoma cells. PET-CT demonstrated a right-sided submandibular mass measuring $4 \times 5.5 \times 4 \mathrm{~cm}$ without involvement of adjacent structures (Fig. 1A and B) as well as a $2 \times 2 \times 2 \mathrm{~cm}$ mass in the upper lobe of the left lung, both with intense 18-FDG uptake. No enlarged or high-uptake lymph nodes were identified. The patient underwent resection of the submandibular gland along with selective neck dissection of level I-III of the cervical lymph nodes. All nerves were spared and the patient had no postoperative sequelae. The operation was macroscopically but not microscopically radical, and the patient received adjuvant radiotherapy (66 Gy in 33 fractions over five weeks) and a carboplatin-etoposide chemotherapy regimen.

After completion of radiotherapy and chemotherapy, the patient underwent lobectomy for the left-sided lung cancer which subsequently metastasized to the right lung. The patient died 19 months after excision of the submandibular tumor due to the lung cancer.

Histopathology and immunohistochemistry. Formalin-fixed and paraffin-embedded (FFPE) tissues from the submandibular and lung resected specimens were sectioned and stained with hematoxylin and eosin according to standard protocols. Immunohistochemistry was performed using the Ventana BenchMark ULTRA platform (Ventana Medical Systems, Tucson, AZ, USA) except for FLI-1, which was processed with the EnVision ${ }^{\mathrm{TM}}$ system (Dako, Glostrup, Denmark). The following antibodies were used: Ki-67 (clone MIB-1, code M724001, mouse anti-human; 1:100; Dako), CD56 [clone 1B6, code NCL-CD56-1B6, mouse antihuman; 1:50; Novocastra (Newcastle, UK)], synaptophysin [clone MRQ-50, code 760-4595, rabbit anti-human; 1:150; Roche (Mannheim, Germany)], chromogranin A (polyclonal, code A043001, rabbit anti-human; 1:2,000; Dako), p63 (clone 4A4, code 790-4509, mouse anti-human, ready-to-use; Roche), S-100 (polyclonal, code Z0311, rabbit anti-human; 1:4,000), actin (clone 1A4, code M085101, mouse anti-human; 1:2,000), vimentin (clone VIM 3B4, code M7020, mouse antihuman; 1:400), calponin (clone CALP, code M355601, mouse anti-human; 1:500), cytokeratin 5/6 (CK5/6) (clone D5/16 B4, code M723701, mouse anti-human; 1:20), cytokeratin-7 (CK7) (clone OV-TL 12/30, code M701801, mouse anti-human; 1:1,000), CD99 (clone E12, code M3601, mouse anti-human; 1:100), desmin (clone D33, code M076001, mouse anti-human; 1:100) (all from Dako), FLI-1 [clone G146-222, code 554266, mouse anti-human; 1:400, BD Biosciences (San Jose, CA, USA)], CD117 (polyclonal, code A450229, rabbit anti-human; 1:100; Dako), p16 (clone E5H4, code 825-4713, mouse antihuman, ready-to-use; Roche), NUT [clone C52B1, code 3625, rabbit anti-human; 1:50; Cell Signaling Technology (Danvers, MA, USA)], napsin A (clone IP64, code NCL-L-Napsin A, mouse anti-human; 1:400) and TTF-1 (clone SPT24, code NCL-TTF-1, mouse anti-human; 1:100) (both from Novocastra). Negative control sections were incubated identically except for the primary antibody, which was replaced by normal rabbit serum/mouse IgG.

The Danish Data Protection Agency (REG-94-2014) approved the investigation. Written consent from the patient's husband was obtained. The investigation adheres to the tenets of the Declaration of Helsinki (version 2008).

In situ hybridization (ISH). The Epstein-Barr virus (EBER) PNA probe/flourescein kit was used (code Y5200) and visualized with the Dako PNA ISH Detection kit (code K5201) (both from Dako). Five-micron FFPE sections were deparaffinized, rehydrated and processed according to the manufacturer's instructions.

Fluorescence in situ hybridization (FISH). The ZytoLight SPEC EWSR1 dual-color break-apart probe was used (ZytoVision, Bremerhaven, Germany) according to the manufacturer's protocol using the HYBrite platform (Abbott Molecular, Des Plaines, IL, USA). After hybridization, nuclei were counterstained with DAPI (ZytoVision). At least 100 nuclei were counted, and only nuclei where the entire nuclear membrane could be visualized were scored. A signal was considered positive for EWSRl rearrangement when the distance between red and green signals was greater than two diameters of any individual signal. At least $10 \%$ of nuclei should display a split signal for a positive score.

Array comparative genomic hybridization (arrayCGH) analysis. Genomic DNA was isolated from the FFPE LCNEC tumor tissue using the DNeasy ${ }^{\circledR}$ Blood and Tissue kit (Qiagen $\mathrm{GmbH}$, Hilden, Germany). ArrayCGH analysis was subsequently performed using the human genome $\mathrm{CGH}$ microarray 244K oligonucleotide array (G4411B; Agilent Technologies Inc., Palo Alto, CA, USA). The arrayCGH experiment was essentially performed as previously described and as recommended by the manufacturer $(16,17)$. Slides were scanned on an Agilent High-Resolution C Microarray Scanner, followed by data extraction and normalization using Feature Extraction v.10.7.1 (Agilent Technologies) with linear normalization (protocol CGH_107_Sep09). Data analysis was carried out using Nexus Copy Number Software ${ }^{\circledR}$ Discovery Edition v. 7.5 (BioDiscovery Inc., El Segundo, CA, USA) as previously described. The FASST2 segmentation algorithm was used to define non-random regions of CNAs across the genome with a significance threshold set to $\mathrm{p}=1.0 \mathrm{E}-8$. The $\log 2$ ratio thresholds for aberration calls were set to 1.5 for high copy number gain/amplification, 0.3 for gain, -0.3 for loss and -1.5 for homozygous deletion. Each aberration was checked manually to confirm the accuracy of the call. Gender chromosomes and regions partially or completely covered by a previously reported copy number variation (Database of Genomic Variants; http://dgvbeta.tcag.ca/dgv/app/news?ref=NCBI37/ hg19) were excluded from the analysis.

\section{Results}

Histopathology. The submandibular tumor was firm, homogeneous with a shiny cut surface. The tumor did not grow beyond the well-encapsulated submandibular gland. Microscopic examination of the tumor revealed a mainly undifferentiated tumor consisting of large sheets of medium-sized tumor cells with large, vesicular nuclei with conspicuous nucleoli and scarce cytoplasm along with abrupt, isolated squamous components organized in well-demarcated round nests. The latter made up 

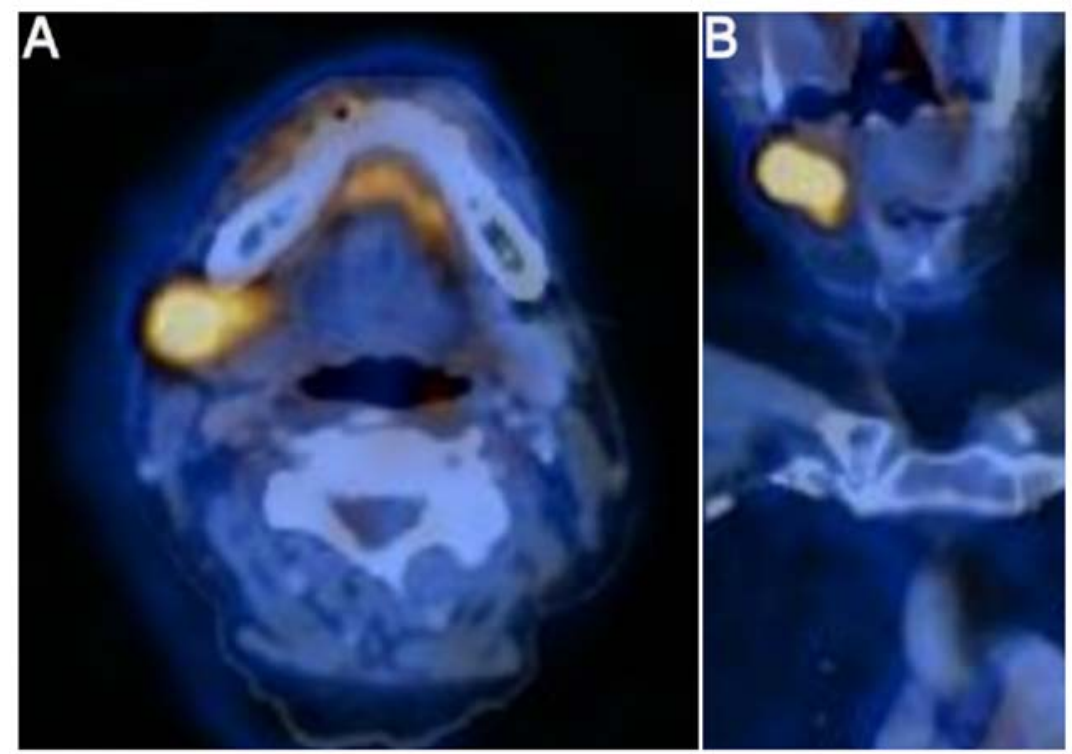

Figure 1. PET-CT scan of the patient at the time of diagnosis. (A) Axial PET-CT image demonstrating intense 18-FDG uptake behind the right angulus of the mandible. (B) Coronal PET-CT showing the well-circumscribed, right-sided submandibular mass displacing the surrounding soft tissue over the midline.
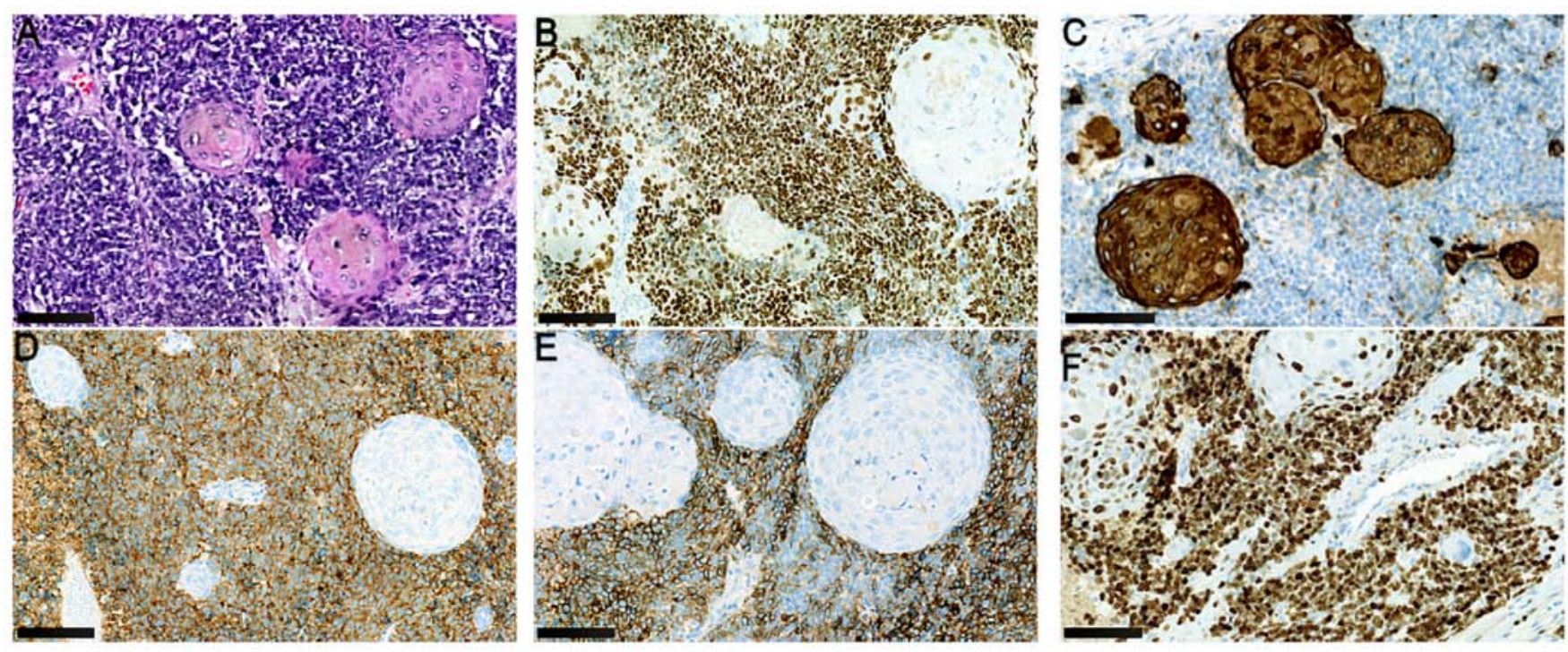

Figure 2. Histology and immunophenotype of the salivary gland combined large cell neuroendocrine carcinoma. (A) Hematoxylin and eosin (H\&E) staining showing an undifferentiated tumor component consisting of medium sized tumor cells with large, vesicular nuclei and scarce cytoplasm along with a squamous component organized in round nests. (B) p63 staining with undifferentiated cells being intensely positive, and the most peripheral cells in the squamous areas being moderately positive. (C) Cytokeratin 5/6 was expressed mainly in the squamous component whereas only scattered undifferentiated cells stained positive. (D and E) The neuroendocrine markers synaptophysin and CD56 were both intensely expressed in the undifferentiated cells and absent in the squamous component. (F) Ki-67 was positive in $95 \%$ of the undifferentiated cells and in $30 \%$ of the squamous cells. Scale bar, $100 \mu \mathrm{m}$.

$\sim 30 \%$ of the tumor (Fig. 2A). Both cell types were positive for p63 whereas primarily the squamous component expressed CK5/6 (Fig. 2B and C). The undifferentiated component was positive for synaptophysin and CD56 whereas the squamous cells were negative for both (Fig. 2D and E). The undifferentiated cells had a Ki-67 index of $95 \%$, whereas the corresponding number for the squamous cells was $30 \%$ (Fig. 2F). Both cell populations were negative for CK7, chromogranin A, S-100, actin, vimentin, calponin, CD117, p16, NUT, napsin A, desmin, CD99, FLI-1 and EBV. TTF-1 showed weak reaction in 5\% of undifferentiated tumor cells. FISH analysis showed that the tumor cells were negative for the Ewing sarcoma specific translocation $\mathrm{t}(11 ; 22)$. All lymph nodes were free of tumor cells. The final histopathologic diagnosis was combined LCNEC of the squamous type and the patient was staged as T3N0M0 (18). The lung tumor was extensively sampled for neuroendocrine and squamous differentiation but with no evidence of either of these components. The lung tumor was also morphologically different from the submandibular tumor and had a distinctly different immunohistochemical profile as presented in Fig. 3 and Table I. The final diagnosis was primary papillary adenocarcinoma of the lung. 

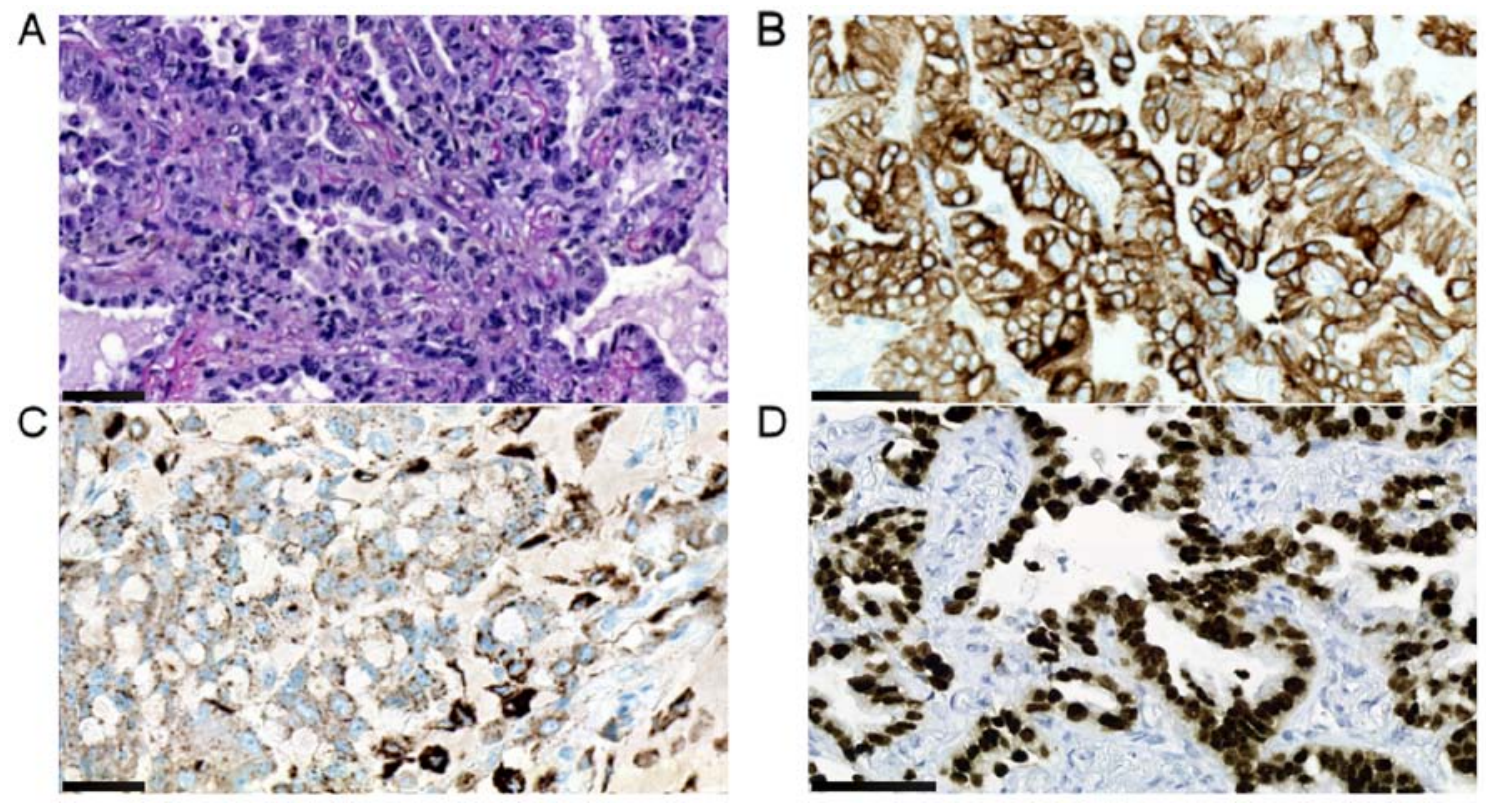

Figure 3. Histology and immunophenotype of the lung papillary adenocarcinoma. (A) Hematoxylin and eosin (H\&E) staining showing an adenocarcinoma with papillary structures growing along fibrovascular cores. Centrally located mucin lakes with isolated tumor fragments were frequent. (B) Cytokeratin 7 was strongly positive in the cytoplasm of the tumor cells. (C) Napsin A showed a coarse, granular cytoplasmic staining pattern in the tumor cells. (D) TTF-1 was intensely expressed in nuclei of tumor cells. Scale bar, $75 \mu \mathrm{m}$.

Table I. Immunohistochemical characteristics of the large cell neuroendocrine carcinoma of the submandibular gland and the papillary adenocarcinoma of the lung.

\begin{tabular}{lccc}
\hline \multicolumn{4}{c}{$\begin{array}{c}\text { Combined large cell } \\
\text { neuroendocrine carcinoma } \\
\text { in submandibular gland }\end{array}$} \\
\cline { 2 - 3 } Antibody & $\begin{array}{c}\text { Undifferentiated } \\
\text { component }\end{array}$ & $\begin{array}{c}\text { Squamous } \\
\text { component }\end{array}$ & $\begin{array}{c}\text { Papillary } \\
\text { adenocarcinoma } \\
\text { in lung }\end{array}$ \\
\hline Cytokeratin 5/6 & - & + & - \\
Cytokeratin 7 & - & - & + \\
p63 & + & + & - \\
TTF-1 & - & - & + \\
Napsin A & - & - & + \\
Synaptophysin & + & - & - \\
CD56 & + & - & - \\
\hline
\end{tabular}

Genomic profile of the LCNEC. In order to genomically characterize the salivary gland LCNEC we performed arrayCGH analysis using a high-resolution $244 \mathrm{~K}$ oligonucleotide array. The results are presented in Table II and in Fig. 4A and B. The tumor had a relatively uncomplicated genomic profile characterized by in particular copy number losses. In total, 10 losses and 4 gains were identified. There was no evidence of gene amplification or homozygous deletion. Losses and gains of whole chromosomes or chromosome arms predominated and included $-3 \mathrm{p},-4,-7 \mathrm{q},-10$ (10pter-q26) $-11,-13,-16 \mathrm{q},+3 \mathrm{q}$ and $+16 p$ (Fig. 4A). In addition, there were a few segmental gains and losses, most notably gain of a $2.3 \mathrm{Mb}$ segment in 9p23-p22.3 including the NFIB oncogene (Fig. 4B). Notably,
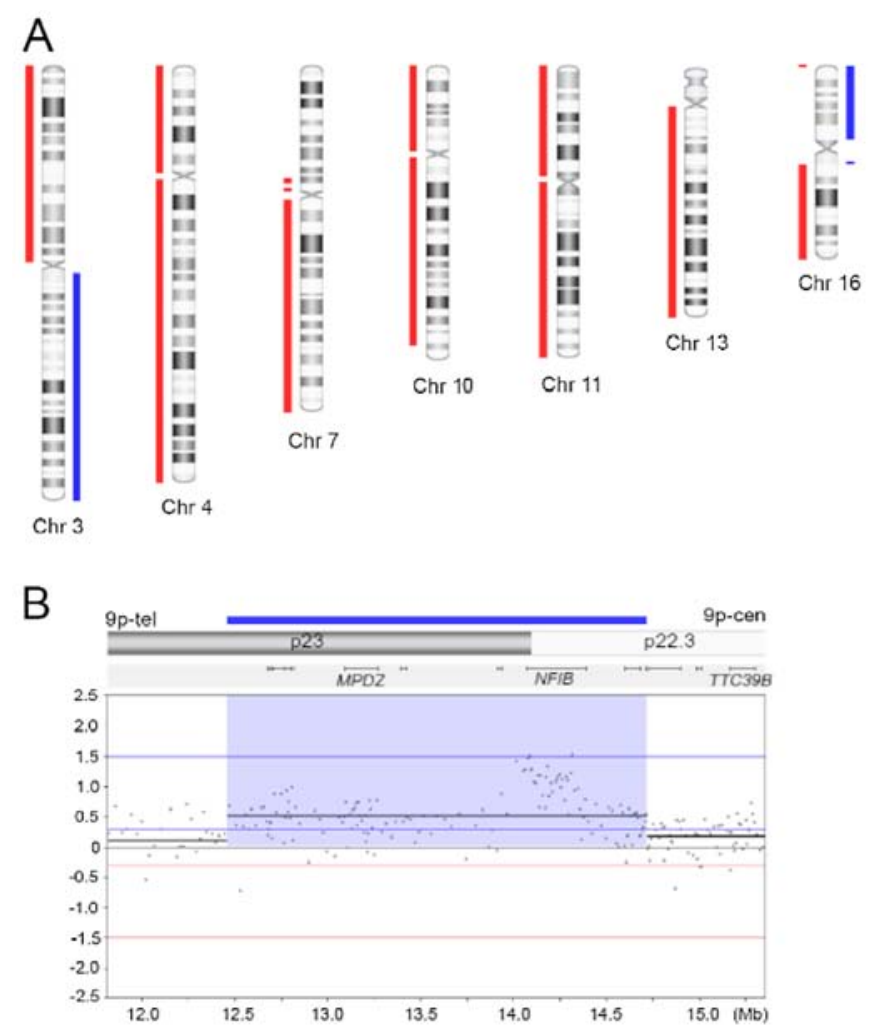

Figure 4. arrayCGH analysis of the salivary gland combined large cell neuroendocrine carcinoma. (A) Major copy number alterations including losses (red vertical lines) and gains (blue vertical lines) of whole chromosomes and chromosome arms. (B) Segmental gain (horizontal blue line) of a 2.3-Mb region in 9p23-p22.3 including the $N F I B$ oncogene.

the loss of 10pter-q26.2 resulted in a breakpoint in the DOCKI gene with loss of the 5'-part of the gene (exons 1-19) and retention of the 3'-part. 
Table II. Copy number alterations detected by high-resolution arrayCGH analysis of the large cell neuroendocrine carcinoma of the submandibular gland.

\begin{tabular}{llcr}
\hline $\begin{array}{l}\text { Cytoband } \\
\text { location }\end{array}$ & $\begin{array}{c}\text { Genomic } \\
\text { event }\end{array}$ & $\begin{array}{r}\text { Region length } \\
(\mathrm{Mb})\end{array}$ & $\begin{array}{r}\text { No. of } \\
\text { genes }\end{array}$ \\
\hline 2q22.1-q36.3 & Gain & 86.1 & 518 \\
$3 \mathrm{p}$ & Loss & 90.4 & 651 \\
$3 \mathrm{q}$ & Gain & 104.4 & 774 \\
4 & Loss & 188.1 & 1,120 \\
$7 \mathrm{q}$ & Loss & 97.4 & 837 \\
$9 \mathrm{p} 23-\mathrm{p} 22.3$ & Gain & 2.3 & 9 \\
$10 \mathrm{pter-q26.2}$ & Loss & 128 & 971 \\
11 & Loss & 131.0 & 1,577 \\
13 & Loss & 85.9 & 587 \\
$16 \mathrm{pter-p13.3}$ & Loss & 0.53 & 31 \\
$16 \mathrm{p} 13.3-\mathrm{q} 12.1$ & Gain & 24.7 & 441 \\
$16 \mathrm{q} 12.1-\mathrm{qter}$ & Loss & 43.2 & 468 \\
$19 \mathrm{q} 13.33-\mathrm{q} 13.42$ & Loss & 1.9 & 111 \\
$19 \mathrm{q} 13.43$ & Loss & 0.7 & 17 \\
\hline
\end{tabular}

$\mathrm{Mb}$, megabase.

\section{Discussion}

Neuroendocrine tumors are a heterogeneous group of lesions that may occur in all visceral subsites in the body (11). They are, however, extremely rare in the salivary glands. Only 10 LCNECs have been reported in the literature, four of which were located in the submandibular gland. In the present study, we report the first case of LCNEC with squamous differentiation, a so-called combined LCNEC. Salivary gland cancers are rare and constitute only $0.3 \%$ of all human malignancies. They originate from the epithelial components of the major and minor salivary glands (12). The origin of salivary gland LCNEC is, however, unknown and to date no neuroendocrine cells have been identified in the salivary glands (8). The rarity of these lesions is further illustrated by the identification of only two cases of parotid LCNEC in a series of 1,675 surgically resected, primary parotid gland tumors (5). However, since a number of different head and neck neoplasms, including those of salivary gland origin, demonstrate focal expression of neuroendocrine markers, the definition of what actually constitutes a 'true' neuroendocrine tumor has been a matter of debate (19). Besides the challenge of histopathological diagnosis of neuroendocrine neoplasms, FNAC of LCNEC is difficult and does not contribute to diagnostic accuracy since it often results in a suggestion of an undifferentiated carcinoma.

Notably, in addition to the submandibular gland LCNEC our patient also had a concurrent lung tumor. Although several histomorphologic variants of LCNEC of the lung have been described, thorough histopathological examination of two different surgical specimens showed an identical image consistent with a primary papillary adenocarcinoma of pulmonary origin. There was no evidence of neuroendocrine differentiation or histopathologic overlap with the submandibular LCNEC, thus excluding the possibility of a metastatic pulmonary lesion $(20,21)$. The well-encapsulated appearance of the submandibular tumor along with the lack of metastases did not call for chemotherapy and/or radiotherapy. No recurrences or metastases of the LCNEC were identified during the 19 months of follow-up.

Genomic profiling of the submandibular gland LCNEC revealed a hypodiploid genome predominated by losses of whole chromosomes or chromosome arms involving chromosomes 3p, 4, 7q, 10, 11, 13, 16q and gains of $3 q$ and 16p. To the best of our knowledge, a similar genomic profile has not been detected in any of the major types of salivary gland carcinomas analyzed to date (16,22-25, unpublished data). In addition, the present case had two particularly interesting copy number alterations, namely gain of a $2.3-\mathrm{Mb}$ segment in 9p23-p22.3, including the $N F I B$ gene and a breakpoint in the $D O C K 1$ gene in $10 \mathrm{q} 26.2$. We previously identified recurrent gains of $N F I B$ in pleomorphic adenomas and carcinoma ex pleomorphic adenomas (26). We have also shown that NFIB, which encodes a transcription factor, is involved in recurrent gene fusions with $H M G A 2$ in pleomorphic adenomas and with $M Y B$ in adenoid cystic carcinomas of the salivary glands (27-29). These observations together with recent arrayCGH studies demonstrating copy number gain/amplification and overexpression of $N F I B$ in human and experimental small cell lung cancers and triple-negative breast cancers further supports the notion that $N F I B$ has oncogenic properties in several types of human neoplasms $(30,31)$. We also detected a breakpoint in the DOCK 1 gene in 10q26.2. This is of special interest because gene fusions involving $D O C K 1$ and at least 5 different partner genes were recently detected in breast cancer and astrocytomas $(25,32)$. Whether DOCK 1 is involved in a gene fusion also in the present case of LCNEC remains to be shown.

Although genomic profiling data is only available from the present case of salivary gland LCNEC, it is interesting to note that this case has several genomic features in common with LCNEC of the lung, including losses of 3p, 4q, 10q, 13q and $16 q$ and gain involving $3 q$ (13-15). Analyses of additional cases of salivary gland LCNEC are, however, necessary to confirm these genomic similarities. Notably, although LCNEC is most commonly found in the lungs it is still a rare tumor that lacks a consensus treatment (33). In the current WHO classification of lung cancers, LCNEC is categorized as a non-small cell lung cancer (non-SCLC) despite the fact that the clinical and biological characteristics are more similar to those of small cell lung cancer (SCLC) $(33,34)$. In addition, several studies favor SCLC chemotherapy regimens for lung LCNECs as compared to non-SCLC regimens $(11,34)$. The response of LCNEC of the salivary glands to chemotherapy is yet to be determined but could prove to be an attractive treatment option in patients with advanced disease.

In conclusion, we report a rare case of LCNEC of the salivary glands and the first case of the combined subtype. The patient was staged as T3N0M0 and radically operated for a well-circumscribed tumor. There was no recurrence or metastasis during the follow-up of 19 months after which the patient died of a concurrent papillary adenocarcinoma of the lung. Continued studies of salivary gland LCNEC may provide new knowledge concerning potential diagnostic biomarkers and 
may ultimately also lead to the identification of new treatment targets for patients with this type of carcinoma.

\section{Acknowledgements}

We thank Pernille Frederiksen and Sanni Pedersen for excellent technical support with immunohistochemistry and FISH, respectively. This study was supported in part by the Region Zealand, the Swedish Cancer Society and BioCARE - a National Strategic Research Program at the University of Gothenburg.

\section{References}

1. Brambilla E, Lantuejoul S, Pugatch B, Chang YL, Geisinger K, Petersen I, Gal A, Meyerson M, Sheppard MN, Hanash SM, et al: Large cell carcinoma. In: World Health Organization Classification of Tumours, Pathology and Genetics, Tumours of the Lung, Pleura, Thymus and Heart. Travis WD, Brambilla E, Müller-Hermelink K and Harris CC (eds). IARC Press, Lyon, pp45-50, 2004.

2. Hui KK, Luna MA, Batsakis JG, Ordóñez NG and Weber R: Undifferentiated carcinomas of the major salivary glands. Oral Surg Oral Med Oral Pathol 69: 76-83, 1990.

3. Casas P, Bernáldez R, Patrón M, López-Ferrer P and GarcíaCabezas MA: Large cell neuroendocrine carcinoma of the parotid gland: Case report and literature review. Auris Nasus Larynx 32: 89-93, 2005.

4. Ueo T, Kaku N, Kashima K, Daa T, Kondo Y, Yoshida K, Suzuki M and Yokoyama S: Carcinosarcoma of the parotid gland: An unusual case with large-cell neuroendocrine carcinoma and rhabdomyosarcoma. APMIS 113: 456-464, 2005.

5. Nagao T, Sugano I, Ishida Y, Tajima Y, Munakata S, Asoh A, Yamazaki K, Muto H, Konno A, Kondo Y, et al: Primary large-cell neuroendocrine carcinoma of the parotid gland Immunohistochemical and molecular analysis of two cases. Mod Pathol 13: 554-561, 2000.

6. Larsson LG and Donner LR: Large cell neuroendocrine carcinoma of the parotid gland: Fine needle aspiration, and light microscopic and ultrastructural study. Acta Cytol 43: 534-536, 1999.

7. Yamamoto N, Minami S, Kidoguchi M, Shindo A, Tokumaru Y and Fujii M: Large cell neuroendocrine carcinoma of the submandibular gland: Case report and literature review. Auris Nasus Larynx 41: 105-108, 2014.

8. Petrone G, Santoro A, Angrisani B, Novello M, Scarano E, Rindi G and Lauriola L: Neuroendocrine tumors of the submandibular gland: Literature review and report of a case. Int J Surg Pathol 21: 85-88, 2013.

9. Kawaratani H, Tsujimoto T, Yoshikawa M, Kawanami F, Shirai Y, Yoshiji H, Morita K and Fukui H: Large cell neuroendocrine carcinoma presenting with neck swelling in the submandibular gland: A case report. J Med Case Rep 7: 81, 2013.

10. Sowerby LJ, Matthews TW, Khalil M and Lau H: Primary large cell neuroendocrine carcinoma of the submandibular gland: Unique presentation and surprising treatment response. J Otolaryngol 36: E65-E69, 2007.

11. Kusafuka K, Ferlito A, Lewis JS Jr, Woolgar JA, Rinaldo A, Slootweg PJ, Gnepp DR, Devaney KO, Travis WD and Barnes L: Large cell neuroendocrine carcinoma of the head and neck. Oral Oncol 48: 211-215, 2012.

12. Barnes L, Eveson JW, Reichart P and Sidransky D (eds): Salivary Glands. In: World Health Organization Classification of Tumours, Pathology and Genetics of Head and Neck Tumours. IARC Press, Lyon, p210, 2005.

13. Peng WX, Shibata T, Katoh H, Kokubu A, Matsuno Y, Asamura H, Tsuchiya R, Kanai Y, Hosoda F, Sakiyama T, et al: Array-based comparative genomic hybridization analysis of high-grade neuroendocrine tumors of the lung. Cancer Sci 96: 661-667, 2005.

14. Ullmann R, Petzmann S, Sharma A, Cagle PT and Popper HH: Chromosomal aberrations in a series of large-cell neuroendocrine carcinomas: Unexpected divergence from small-cell carcinoma of the lung. Hum Pathol 32: 1059-1063, 2001.

15. Walch AK, Zitzelsberger HF, Aubele MM, Mattis AE, Bauchinger M, Candidus S, Präuer HW, Werner M and Höfler H: Typical and atypical carcinoid tumors of the lung are characterized by $11 \mathrm{q}$ deletions as detected by comparative genomic hybridization. Am J Pathol 153: 1089-1098, 1998.
16. Persson F, Winnes M, Andrén Y, Wedell B, Dahlenfors R, Asp J Mark J, Enlund F and Stenman G: High-resolution array CGH analysis of salivary gland tumors reveals fusion and amplification of the FGFR1 and PLAG1 genes in ring chromosomes. Oncogene 27: 3072-3080, 2008.

17. Barrett MT, Scheffer A, Ben-Dor A, Sampas N, Lipson D, Kincaid R, Tsang P, Curry B, Baird K, Meltzer PS, et al: Comparative genomic hybridization using oligonucleotide microarrays and total genomic DNA. Proc Natl Acad Sci USA 101: 17765-17770, 2004.

18. Edge SB, Byrd DR, Compton CC, Fritz AG, Greene FL and Trotti A (eds): AJCC Cancer Staging Manual. 7th edition. Springer-Verlag, New York, pp79-86, 2010.

19. Bell D, Hanna EY, Weber RS, DeMonte F, Triantafyllou A, Lewis JS Jr, Cardesa A, Slootweg PJ, Stenman G, Gnepp DR, et al: Neuroendocrine neoplasms of the sinonasal region. Head Neck: Jun 3, 2015 (Epub ahead of print). doi: 10.1002/hed.24152.

20. Travis WD, Linnoila RI, Tsokos MG, Hitchcock CL, Cutler GB Jr, Nieman L, Chrousos G, Pass H and Doppman J: Neuroendocrine tumors of the lung with proposed criteria for large-cell neuroendocrine carcinoma. An ultrastructural, immunohistochemical, and flow cytometric study of 35 cases. Am J Surg Pathol 15: 529-553, 1991.

21. Jiang SX, Kameya T, Shoji M, Dobashi Y, Shinada J and Yoshimura H: Large cell neuroendocrine carcinoma of the lung: A histologic and immunohistochemical study of 22 cases. Am J Surg Pathol 22: 526-537, 1998.

22. Persson M, Andrén Y, Moskaluk CA, Frierson HF Jr, Cooke SL, Futreal PA, Kling T, Nelander S, Nordkvist A, Persson F, et al: Clinically significant copy number alterations and complex rearrangements of $M Y B$ and $N F I B$ in head and neck adenoid cystic carcinoma. Genes Chromosomes Cancer 51: 805-817, 2012.

23. Zhang L, Mitani Y, Caulin C, Rao PH, Kies MS, Saintigny P, Zhang N, Weber RS, Lippman SM and El-Naggar AK: Detailed genome-wide SNP analysis of major salivary carcinomas localizes subtype-specific chromosome sites and oncogenes of potential clinical significance. Am J Pathol 182: 2048-2057, 2013.

24. Jee KJ, Persson M, Heikinheimo K, Passador-Santos F, Aro K, Knuutila S, Odell EW, Mäkitie A, Sundelin K, Stenman G, et al: Genomic profiles and CRTC1-MAML2 fusion distinguish different subtypes of mucoepidermoid carcinoma. Mod Pathol 26: 213-222, 2013.

25. Mitelman F, Johansson B and Mertens F (eds): Mitelman Database of Chromosome Aberrations and Gene Fusions in Cancer. http://cgap.nci.nih.gov/Chromosomes/Mitelman.

26. von Holstein SL, Fehr A, Persson M, Nickelsen M, Therkildsen MH, Prause JU, Heegaard S and Stenman G: Lacrimal gland pleomorphic adenoma and carcinoma ex pleomorphic adenoma: Genomic profiles, gene fusions, and clinical characteristics. Ophthalmology 121: 1125-1133, 2014.

27. Geurts JM, Schoenmakers EF, Röijer E, Aström AK, Stenman G and van de Ven WJ: Identification of NFIB as recurrent translocation partner gene of HMGIC in pleomorphic adenomas. Oncogene 16: 865-872, 1998.

28. Persson M, Andrén Y, Mark J, Horlings HM, Persson F and Stenman G: Recurrent fusion of $M Y B$ and $N F I B$ transcription factor genes in carcinomas of the breast and head and neck. Proc Natl Acad Sci USA 106: 18740-18744, 2009.

29. Stenman G, Persson F and Andersson MK: Diagnostic and therapeutic implications of new molecular biomarkers in salivary gland cancers. Oral Oncol 50: 683-690, 2014.

30. Han W, Jung EM, Cho J, Lee JW, Hwang KT, Yang SJ, Kang JJ, Bae JY, Jeon YK, Park IA, et al: DNA copy number alterations and expression of relevant genes in triple-negative breast cancer. Genes Chromosomes Cancer 47: 490-499, 2008.

31. Dooley AL, Winslow MM, Chiang DY, Banerji S, Stransky N, Dayton TL, Snyder EL, Senna S, Whittaker CA, Bronson RT, et al: Nuclear factor $\mathrm{I} / \mathrm{B}$ is an oncogene in small cell lung cancer. Genes Dev 25: 1470-1475, 2011.

32. Yoshihara K, Wang Q, Torres-Garcia W, Zheng S, Vegesna R, Kim H and Verhaak RG: Tumours of the lung. In: The landscape and therapeutic relevance of cancer-associated transcript fusions. Oncogene 34: 4845-4854, 2015.

33. Iyoda A, Makino T, Koezuka S, Otsuka H and Hata Y: Treatment options for patients with large cell neuroendocrine carcinoma of the lung. Gen Thorac Cardiovasc Surg 62: 351-356, 2014.

34. Travis WD, Brambilla E, Müller-Hermelink K and Harris CC (eds): World Health Organization Classification of Tumours, Pathology and Genetics, Tumours of the Lung, Pleura, Thymus and Heart. IARC Press, Lyon, p10, 2004. 